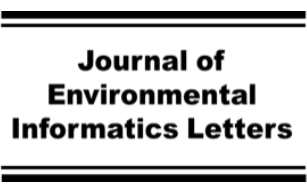

www.iseis.org/jeil

\title{
Plant Selection of Ecological Embankment for Nitrogen Removal in Lihe, China
}

\author{
M. N. Li ${ }^{1}$, L. H. Wang ${ }^{1 *}$, D. Zheng ${ }^{1}$, X. Ge ${ }^{1}$, R. Cheng ${ }^{1}$, and M. Y. Wang ${ }^{1}$ \\ ${ }^{I}$ School of Environment and Civil Engineering, Jiangnan University, 1800 Lihu Avenue, Wuxi, Jiangsu 214122, China.
}

Received 17 September 2019; revised 23 October 2019; accepted 2 November 2019; published online 10 December 2019

\begin{abstract}
Eutrophication is one of major environmental problems in the Lihe area, China. Reducing the entry of external nitrogen is an effective way to alleviate this problem. Plants, growing in ecological embankment can absorb nitrogen from soil and effectively achieve the purpose of reducing external nitrogen into the water. In order to choose suitable buffer zone plants, this paper explores the viability under three nitrogen concentrations (low, middle, and high) in soil of 13 common plants around Lihe area and their nitrogen utilization ability. Results show that there is no obvious relationship between the absorption and utilization of nitrogen and classifications of plants. JNL (Jasminum nudiflorum Lindl.) possesses high plant total nitrogen concentration (PTN), PTN increase ratio, nitrate reductase activity (NRA), chlorophyll content, and excellent chlorophyll fluorescence parameters under the three nitrogen levels, which demonstrates that JNL adapts well in three nitrogen environments and has a high nitrogen absorption capacity. Therefore, it is the first candidate for Lihe ecological embankment. In addition, BML (Buxus megistophylla Levl.), SJL (Sophora japonica Linn.), OJKJ (Ophiopogon japonicus (Linn. f.) Ker-Gawl.), and RPL (Robinia pseudoacacia Linn.) are also promising candidates. This article provides a technical reference for the establishment of Lihe ecological embankment, and the suggested candidate plants include three classifications (arbor, shrub, and herb), which is not only conducive to the local ecosystem stability, but also in line with the landscape design concept.
\end{abstract}

Keywords: Lihe River; flora; ecological embankment; soil nitrogen removal.

\section{Introduction}

Eutrophication caused by nutrient overloading, especially the nitrogen nutrient, is a serious problem in many water ecosystems, leading to degradation of water quality, algae bloom, and loss of biodiversity (Mo et al., 2017). A variety of approaches have been applied to tackle this problem, including physical, chemical, biological and ecological methods, such as deep aeration, coacervation, and biomanipulation. However, many of these conventional methods have driven out in practice to be costly or environmentally unfriendly. Any single method cannot solve the eutrophication problem, and the most effective method is to control the nitrogen entering the water body.

Artificial wetland plants play an important role in the removal of nitrogen from soil. Excess nitrogen in soil are directly removed by their own tissue absorption (Stottmeister et al., 2003); better more, plant roots release oxygen to soil, which cause aerobic, anoxic, and anaerobic conditions around the rhizosphere (Korol et al., 2016; Weller et al., 2016). Oxygen-rich area is beneficial to facilitate the process of ammonia nitrogen nitrifycation and nitrate nitrogen denitrification, which promotes the conversion and removal of nitrogen (Xu et al., 2016; Zhu et al., 2017). In addition, plant rhizosphere microorganisms are also critical in the absorption of nitrogen (Truu et al.,

* Corresponding author. Tel.: +(86) 0510-85326581

E-mail address: wanglihong@jiangnan.edu.cn (L. H. Wang).

ISSN: 2663-6859 print/2663-6867 online

(C) 2019 ISEIS All rights reserved. doi:10.3808/jeil.201900021.
2015; Yu et al., 2019). The essence of plants to remove nitrogen from the soil is the life process of plants using nitrogen, that is, the plants absorb a large amount of nitrogen in the soil as its own growth nutrients and achieve the removal of nitrogen from the soil (Zhang et al., 2016; Ge et al., 2018). There are differences in growth rates, nutrient requirements, absorption capacity, and promoting microbial growth of various kinds of plants. Thus, the ability of different plants to absorb eutrophic salts in soil is worthy to be explored (Rezania et al., 2016; Jasrotia et al., 2017; Srivastava et al., 2017; Liu et al., 2018; Yu et al., 2018).

Ecological embankment refers to the land adjacent to or directly affecting a part of the water body and has a certain ecological purification effect (Uusi-Kämppä and Jauhiainen, 2010; Stutter et al., 2012). It is worthy to mention that the ecological embankment zone is a broad area, requiring special management and maintenance, rather than a narrow area along the river bank (Zhou et al., 2012; Kuglerová et al., 2014). Selectively constructing vegetation on the shores of eutrophic water bodies can repair the pollution of shore soils and trap the external pollution hazards of buffered water (Zhang et al., 2010; Sweeney and Newbold, 2014; Hille et al., 2018). Any changes in one element or the processes of biological and physical of ecological embankment will cause fluctuations in result of nitrogen removal capacity. Vegetation is the prerequisite for achieving in situ restoration of plants, and it plays an important role in building a wellconstructed shore zone with ecological purification (Zhang et al., 2017; Ma, 2018; Schilling et al., 2018). Selecting plants that 
are suitable for shoreline growth and have a strong ability to absorb nitrogen is the key to rehabilitating the soil of eutrophic lakes and reducing the exogenous nitrogen into the water body (Aguiar et al., 2015; Cao et al., 2018; Song et al., 2018).

At present, domestic and foreign studies using plant in situ remediation techniques to control eutrophication of water bodies have mostly focused on the water environment, or compared changes in total nitrogen in surface runoff (Zhou et al., 2016; Korol et al., 2016; Chen et al., 2017; Zak et al., 2018). Studies on the allocation of terrestrial plant communities in riparian zones are rarely reported. For example, Korol, Ahn, and Noe explored the direct and indirect impacts of three plants on freshwater mesocosms and concluded that early-successional annual plant communities played an important role in the development of ecosystem $\mathrm{N}$ multifunctionality in newly created wetland soils (Korol et al., 2016). Chen et al. (2016) examined effects on density and diversity of root organic exudates of four wetland plants and concluded that root exudates affected the rhizosphere microbe diversity and nutrient removal. Zak et al. (2018) established lab-scale Alnus glutinosa (L.) to explore its capability to retain various nitrogen $(\mathrm{N})$ species within the first three years after construction. There are few studies on using plants to reduce the content of nitrogen in the soil, not to mention in specific area of Lihe. What's more, it is important to explore method to establish an effective ecological buffer zone in order to reduce the inflow of external nitrogen into the water body.

Therefore, the objective of this research is to explore suitable plants for construction of Lihe ecological embankment. Nitrogen absorption abilities of three types of woody plants under different nitrogen levels will be investigated by measuring chlorophyll content, chlorophyll fluorescence parameters, nitrate reductase activity, nitrogen content in plants, and nitrogen content in soil. Results will be expected to reveal plants with strong nitrogen removal effect on the riparian in soil and provide a reference for the construction of riparian zones with ecological purification effect.

\section{Materials and Methods}

\subsection{Materials and Chemicals}

In this experiment, three types of widespread plants (trees, shrubs, and herbs) in the Taihu Lake area were selected: six species of trees (Sophora japonica Linn. (SJL), Robinia pseudoacacia Linn. (RPL), Pterocarya stenoptera C. DC (PSC), Sapindus mukorossi Gaertn. (SMG), Cinnamomum camphora (Linn) Presl (CCP), and Magnolia grandiflora L. (MGL); five kinds of shrubs (Jasminum nudiflorum Lindl. (JNL), Buxus megistophylla Levl. (BML), Hibiscus syriacus Linn. (HSL), Nandina domestica (ND), and Euonymus kiautschovicus (EK), and two species of herbs (Ophiopogon japonicus (Linn.f.) KerGawl. (OJKG) and Sagittaria trifolia L. var. sinensis (Sims) Makino (SLSM) were used as observation objects (For convenience, the capital letter abbreviations in parentheses above will represent all kinds of plants below). Two-year-old seedlings with similar growth, vigorous leaf growth and without disease spots were chosen as test materials, and the seedlings were bought from the Xiaxi Flower Market in Changzhou city, China.

All chemicals (sodium dihydrogen phosphate, disodium hydrogen phosphate, potassium nitrate, concentrated hydrochloric acid, $\alpha$-naphthylamine, sodium nitrite, potassium dihydrogen phosphate, concentrated sulfuric acid, ammonium molybdate, stannous chloride, quartz sand, 30\% sodium hydroxide, trichloroacetic acid, hydrogen peroxide, boric acid, potassium sulfate, copper sulfate, dimethyl sulfoxide, potassium persulfate, Ascorbic acid, Potassium antimony tartrate) were purchased from Sinopharm Chemical Reagent Co., Ltd. with analytical grade, and used as received without further purification.

\subsection{Cultivation of Plants}

The culture substrate was taken from the soil of the Taihu Lake bund. The basic physiochemical properties of the tested soil were as follows: soil depth $0 \sim 30 \mathrm{~cm}, \mathrm{pH} 5.6$, total phosphorus $0.446 \mathrm{~g} / \mathrm{kg}$, total potassium $3.024 \mathrm{~g} / \mathrm{kg}$, total nitrogen $1.20 \mathrm{~g} / \mathrm{kg}$, available nitrogen $140.32 \mathrm{mg} / \mathrm{kg}$, and organic matter $28 \mathrm{~g} / \mathrm{kg}$. Each pot contained $5.0 \mathrm{~kg}$ of $1 \mathrm{~cm}$ diameter sieved airdried soil, watering for $2 \mathrm{~L}$ at the first time. Experiment was performed when transplanted species grew stable. The water management during experimental period was determined by the humidity of the soil, approximately $200 \mathrm{~mL}$ DI was used each time.

According to the soil nitrogen and phosphorus concentration in the Lihe zone, six treatments were set up: three nitrogen levels at total phosphorus concentration: low nitrogen (1.2 $\mathrm{g} / \mathrm{kg})$, medium nitrogen $(1.8 \mathrm{~g} / \mathrm{kg})$, and high nitrogen $(2.6$ $\mathrm{g} / \mathrm{kg}$ ); another three phosphorus levels under total nitrogen concentration: low phosphorus $(0.3 \mathrm{~g} / \mathrm{kg})$, medium phosphorus $(0.5$ $\mathrm{g} / \mathrm{kg})$, high phosphorus $(0.7 \mathrm{~g} / \mathrm{kg})$. Three replicates for each treatment group.

\subsection{Treatment of Plants}

Leaves, which grew in the same direction, same leaf position and healthy condition were pick, then rinsed 5 times with deionized water. Residual water was absorbed by filter paper, then leaf veins were removed. Indicators, such as chlorophyll content, chlorophyll fluorescence, nitrate reductase activity, total leaf nitrogen content, total leaf phosphorus content were tested. At the same time, soil samples were taken and the contents of total nitrogen and total phosphorus in the soil were determined. All details of testing methods were listed in following.

\subsection{Testing Methods}

\subsubsection{Chlorophyll Content}

The Chlorophyll content was measured by using dimethyl sulfoxide method (Liu and Li, 2007). $0.2 \mathrm{~g}$ leaves of different plants were cut into filaments and put into a test tube, $10 \mathrm{~mL}$ dimethyl sulfoxide added, and sealed. Tubes were kept in $65^{\circ} \mathrm{C}$ oven for $1 \sim 3 \mathrm{~h}$ to extract (stop when leaves complete whiten). Took the supernatant and measured the optical density at 663 $\mathrm{nm}$ and $645 \mathrm{~nm}$ (blank with dimethyl sulfoxide). The chloro- 
phyll extract of dimethyl sulfoxide method was the same as that of acetone extract method. Thus, the chlorophyll content can be calculated according to the acetone method.

The maximum absorption wavelengths of chlorophyll a and chlorophyll $\mathrm{b}$ in $80 \%$ acetone are $664.5 \mathrm{~nm}$ and $647 \mathrm{~nm}$, respectively. The formulas for calculating the chlorophyll content $(\mathrm{mg} / \mathrm{L})$ are:

$$
\begin{aligned}
& C_{a}=12.63 O D_{664.5}-2.52 O D_{647} \\
& C_{b}=20.47 O D_{647}-4.73 O D_{664.5} \\
& C_{T}=C_{a}+C_{b}=7.09 O D_{664.5}+17.95 O D_{647}
\end{aligned}
$$

where, $C_{a}$ and $C_{b}$ are the concentrations of chlorophyll a and chlorophyll b, respectively; $C_{T}$ is the total concentration of chlorophyll a and chlorophyll $\mathrm{b}$ in $\mathrm{mg} / \mathrm{L}$.

The chlorophyll content per unit mass or area of the measured material can be further calculated by the following formula:

$$
C=\frac{C_{T} \times V}{A \times 1000}
$$

where, $C$ is chlorophyll concentration, $\mathrm{mg} / \mathrm{L} ; V$ is the total volume of the extraction solution, $\mathrm{mL} ; A$ is the fresh weight or area of the leaf, $g$ or $\mathrm{dm}^{2}$.

\subsubsection{Chlorophyll Fluorescence (Li et al., 2009)}

The PAM-2100 pulse modulation fluorometer produced by German WALZ company was used to measure the fluorescence of plant leaves in vivo. Leaves were dark-adapted for 20 $\min$. The initial fluorescence $\mathrm{F}_{0}$ was measured after the detection light $\left(<0.05 \mu \mathrm{mol} / \mathrm{m}^{2} / \mathrm{s}\right)$ was irradiated, and maximum photochemical quantum yield Fm was tested by irradiation with saturated pulsed light $\left(12000 \mu \mathrm{mol} / \mathrm{m}^{2} / \mathrm{s}\right)$. After turning on the endogenous actinic light $\left(180 \mu \mathrm{mol} / \mathrm{m}^{2} / \mathrm{s}\right)$, the photosynthetic saturated pulsed light (1 pulse) was irradiated once, and the fluorescence parameters and fluorescence quenching curve under the light adaptation were measured at regular intervals. After the capture efficiency $\Phi P S I I$ (primary light energy capture efficiency of PSII in the presence of active light) was stable, the electron transfer rate ETR of PSII was calculated automatically by the instrument.

\subsubsection{Nitrate Reductase Activity (Liu and Li, 2007)}

Freshly retrieved leaves were washed with deionized water, and then drilled into a disc (diameter about $1 \mathrm{~cm}$ ) with a drill. Discs were blotted dry by absorbent paper, weighed about $1.0 \sim 1.5 \mathrm{~g}$ and immersed in two different solutions: (1) 0.1 $\mathrm{mol} / \mathrm{L}$ phosphate buffer solution $(\mathrm{pH}=7.5) 5 \mathrm{~mL}+$ distilled water $5 \mathrm{~mL}$; (2) $0.1 \mathrm{~mol} / \mathrm{L}$ phosphate buffer $(\mathrm{pH}=7.5) 5 \mathrm{~mL}+$ $0.2 \mathrm{~mol} / \mathrm{L} \mathrm{KNO}_{3} 5 \mathrm{~mL}$. Ultrasonic to ensure the leaves sink in solution. Flasks were placed in a $30{ }^{\circ} \mathrm{C}$ water bath and kept in the dark for 30 minutes.

$1 \mathrm{~mL}$ reaction solution, $2 \mathrm{~mL}$ sulfonamide reagent, and 2 $\mathrm{mL} \alpha$-naphthylamine reagent were mixed in a tube, leave for $30 \mathrm{~min}$ and tested in a spectrophotometer $(O D=520 \mathrm{~nm}) . \mathrm{NO}_{2}$ content was calculated from the standard curve.

\subsubsection{Total Nitrogen Content in Leaves}

Trace Kjeldahl method (Liu and Li, 2007) was applied to determine the total nitrogen content in leaves.

Extraction of samples: Duplicates of $0.1000 \sim 0.5000 \mathrm{~g}$ of samples dried to constant weight (depending on the nitrogen content of the sample, generally $1 \sim 3 \mathrm{mg}$ nitrogen is appropriate). One sample was placed in a $10 \mathrm{~mL}$ centrifuge tube, added $5 \mathrm{~mL}$ of $5 \%$ trichloroacetic acid solution and warmed in a 90 ${ }^{\circ} \mathrm{C}$ water bath for extract $15 \mathrm{~min}$, keeping stirring. Cooled down to room temperature, centrifuged at $4000 \mathrm{r} / \mathrm{min}$ for $15 \mathrm{~min}$ and discard the supernatant. Washed with 5\% trichloroacetic acid 2 to 3 times, centrifuge, discard the supernatant. Finally, wash the precipitate with ammonia-free distilled water, place the precipitate on filter papers, dried at $50{ }^{\circ} \mathrm{C}$ to constant weight.

Sample digestion: Experimental tube added sample for determination of total nitrogen; control tube was not added any samples. Carefully to place all samples in the bottom of the digestive tube. Added $5 \mathrm{~mL}$ of concentrated sulfuric acid and 0.3 $\sim 0.5 \mathrm{~g}$ of mixed catalyst to each digestion tube, soaked samples for several hours or left them overnight. Covered a small funnel at the mouth of the tube and heated the digestion on the far-infrared cooking furnace. The temperature can be slightly lower at the beginning to prevent the contents from rising to the nozzle. If there was too much foam, added $2 \sim 3$ drops of absolute ethanol through a small funnel. When a white mist appears at the mouth of the tube and the foam is no longer produced, the temperature can be gradually raised to make the liquid in the digestive tube slightly boil until the brownish color of the digestive liquid disappears and all become clear and transparent. During the digestion process, if black particles were found in the upper part of the digestive tube, the digestive tube should be carefully rotated and rinsed with digestive fluid to ensure the sample was completely digested. In order to ensure the complete digestion reaction, heating can be continued for 1 hour after the digestion fluid is clarified. The entire digestion process generally takes 3 to 4 hours. If the digestion time is too long, nitrogen loss may be caused.

Constant volume: Digested solution cooled to room temperature and constant volume to $100 \mathrm{~mL}$ with ammonia-free water.

Distillation and titration: (1) Water vapor washing of the instrument: first added $2 / 3$ volume of distilled water to the steam generator (added a few drops of concentrated sulfuric acid in advance to make it acidic, then added a few drops of methyl red indicator, and added a small amount of zeolite to prevent explosion boiling). Opened the clip under the funnel and heated it to boiling with an electric furnace to allow water vapor to pass into all parts of the instrument to achieve the cleaning purpose. Placed an Erlenmeyer flask at the lower end of the con- 
denser to receive the condensate. Then closed the clip under the funnel and continued washing with steam for 5 minutes. After flushing, clamped the rubber tube between the steam generator and the collector. The waste liquid in the vacuum distillation flask was siphoned into the collector due to cooling, and the piston at the lower end of the collector was opened to discharge the waste liquid. Wash instrument 2 to 3 times in this way. Placed a triangle bottle containing the boric acid-indicator mixture at the lower end of the condenser tube, so that the lower mouth of the condenser tube was completely immersed $0.5 \mathrm{~cm}$ below the liquid surface and distilled for 1 to 2 minutes. If the color of solution in triangle did not change, it mean that the inside of the distillation unit has been cleaned. Remove the triangular flask and distill for another $1 \sim 2$ minutes. Rinse the lower end of the condenser tube with distilled water. Turn off the electric furnace, and the instrument can be used for measuring samples. (2) Determination of standard ammonium sulfate: Added $20 \mathrm{~mL}$ of boric acid-indicator mixture (it should be purplish red) to the conical flask, take this conical flask at the lower end of the condensing tube, and immerse the outlet of the condensing tube in the solution. Be sure to open the collector plunger before adding the sample to prevent the liquid in the triangular flask from sucking back. Accurately pipetted $2 \mathrm{~mL}$ of ammonium sulfate standard solution into the funnel. Carefully opened the clip under the funnel to slowly flow the ammonium sulfate solution into the distillation flask. Repeated the washing of the funnel three times with a small amount of ammonia-free distilled water (about $1 \sim 2 \mathrm{~mL}$ each time) and transferred them to a distillation flask. Then slowly added $10 \mathrm{~mL}$ of $30 \%$ sodium hydroxide lye to the distillation bottle through the funnel. When the sodium hydroxide lye has not flowed over, closed the clamp. Then added about $50 \mathrm{~mL}$ of ammonia-free distilled water to the funnel and open the clamp slowly, so that half of the distilled water flows into the distillation flask, and the other half of the distilled water remains in the funnel for closing the funnel. Closed the collector piston and heated the steam generator. At this time, the boric acid-indicator mixed solution in the triangular flask gradually changed from purple-red to green due to absorption of ammonia. From the beginning of the discoloration, moved the triangle flask after $3 \sim 5$ minutes of distillation, left the inside of the distillation bottle about $1 \mathrm{~cm}$ away from the lower opening of the condensation tube, washed the lower opening of the condensation tube with a small amount of ammonia-free distilled water, and continued the distillation for about 1 minute. For distillation, remove the Erlenmeyer flask and cover the watch glass. Another $2 \mathrm{~mL}$ of ammonia-free distilled water was used instead of ammonium sulfate solution for blank determination. The triangle flasks of each distillation were titrated together, and the average of the three titrations was used to calculate the nitrogen content, and the results were compared with the standard values. After each distillation, remove the electric furnace, clamp the rubber tube connected between the steam generator and the collector, removed the waste liquid and repeatedly cleaned it with ammonia-free distilled water before the next sample distillation.

Distillation of samples and blanks: $5 \sim 10 \mathrm{~mL}$ of the diluted sample digestion solution added to the distillation flask through the funnel, and then wash the funnel with a small amount of ammonia-free distilled water for several times. The rest of the operation is performed according to the standard ammonium sulfate distillation method.

Titration: titrate with a standard solution of $0.01 \mathrm{~mol} / \mathrm{L}$ hydrochloric acid, until the boric acid-indicator mixture in the triangle flask gradually changed from green to light purple red. This is the end point of the titration. The titration amount was calculated as follows:

$N T(\%)=\frac{C \times(A-B) \times 14 \times V_{T}}{W \times 1000 \times V_{s}} \times 1000$

where, $C$ is the hydrochloric acid standard solution $(0.01$ $\mathrm{mol} / \mathrm{L}) ; A$ is the average amount $(\mathrm{mL})$ of hydrochloric acid standard solution $(0.01 \mathrm{~mol} / \mathrm{L})$ used in titrating the sample; $B$ is the average amount $(\mathrm{mL})$ of the hydrochloric acid standard solution $(0.01 \mathrm{~mol} / \mathrm{L})$ used in the titration blank; $W$ is the sample weight $(\mathrm{g}) ; V_{T}$ is the total volume of digestive juice $(\mathrm{mL}) ; V_{s}$ is the volume of digestive juice $(\mathrm{mL})$ taken during the measurement; 14 is the atomic mass of nitrogen $(\mathrm{g})$.
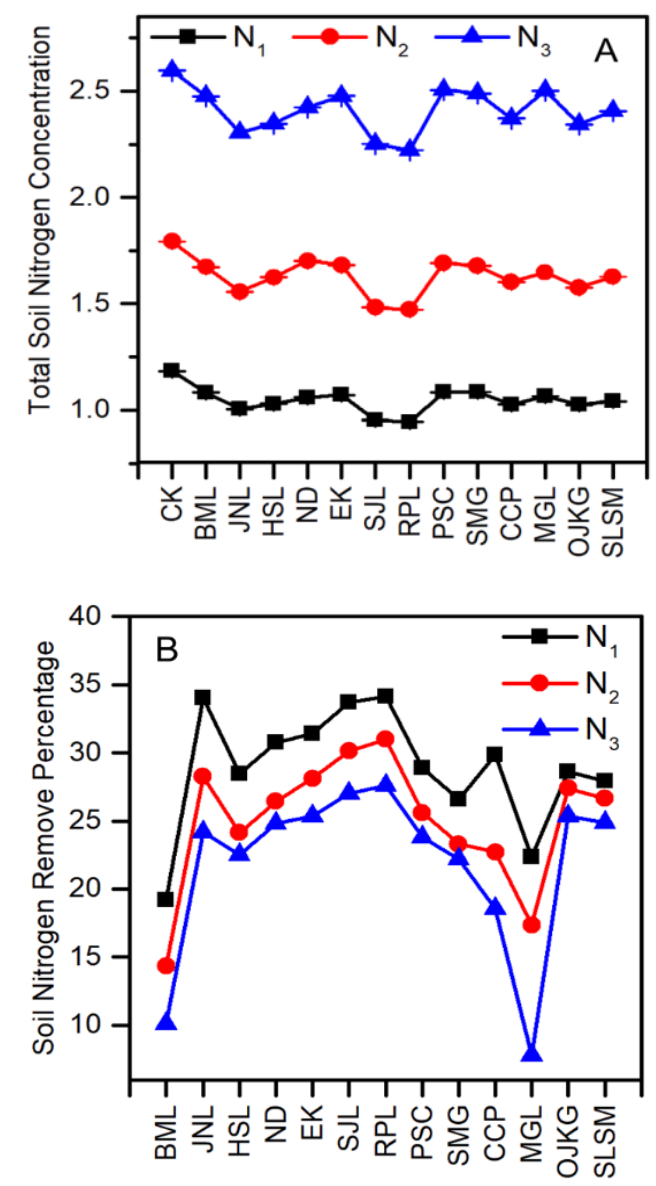

Figure 1. Total nitrogen concentration in soil (A) and soil nitrogen remove ratio (B) for all kinds of plants under three different nitrogen concentration. 

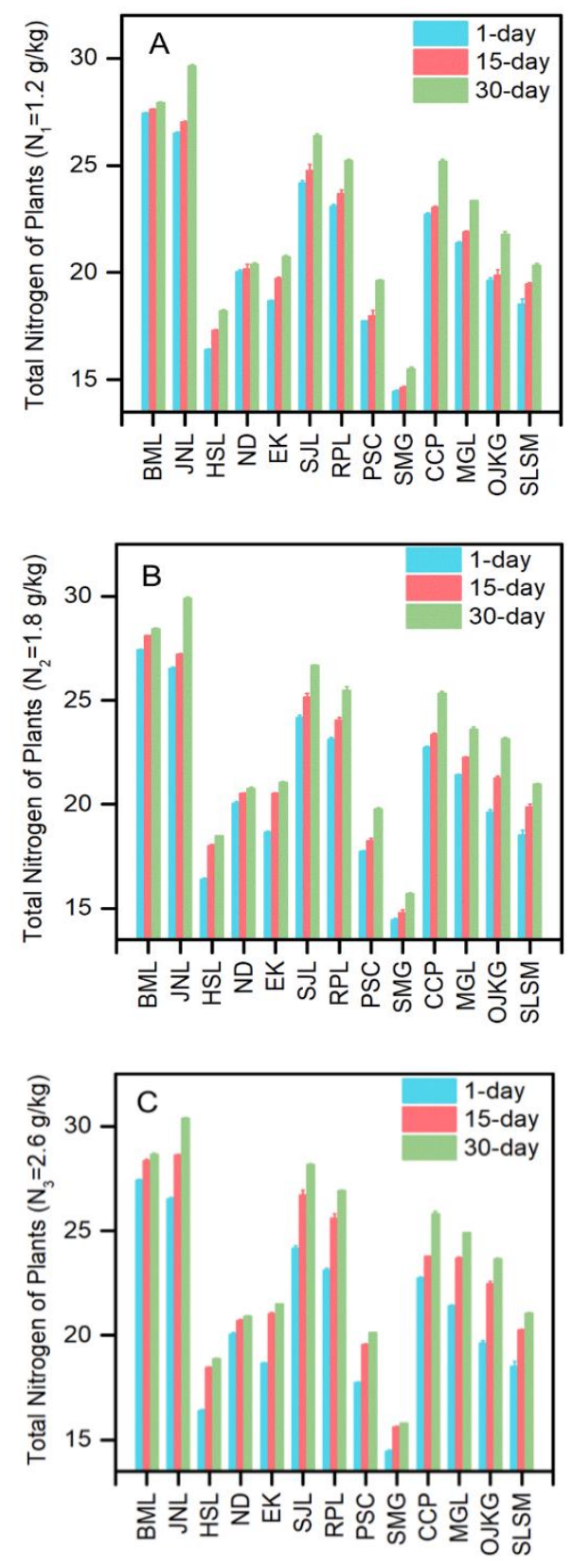

Figure 2. Total nitrogen concentration in plants during culture under three nitrogen levels (A) $\mathrm{N}_{1}=1.2 \mathrm{~g} / \mathrm{kg}$, (B) $\mathrm{N}_{2}=1.8 \mathrm{~g} / \mathrm{kg}$, and $(\mathrm{C}) \mathrm{N}_{3}=2.6 \mathrm{~g} / \mathrm{kg}$.

\subsubsection{Total Nitrogen in Soil}

Basic potassium persulfate digestion method (Jiang and Pan, 2010) was chosen to detect the total nitrogen concentration in soil (Xie et al., 2018).

Preparation of samples: $0.01 \mathrm{~g}$ sample was added into a $250 \mathrm{~mL}$ stoppered triangle flask, mixed with $100 \mathrm{~mL}$ ammoniafree water and $50 \mathrm{~mL}$ alkaline potassium persulfate solution. Sterilized in an autoclave. Digested sample was transferred into a $250 \mathrm{~mL}$ volumetric flask, added $10 \mathrm{~mL}$ of hydrochloric acid, then constant volume with ammonia-free water.
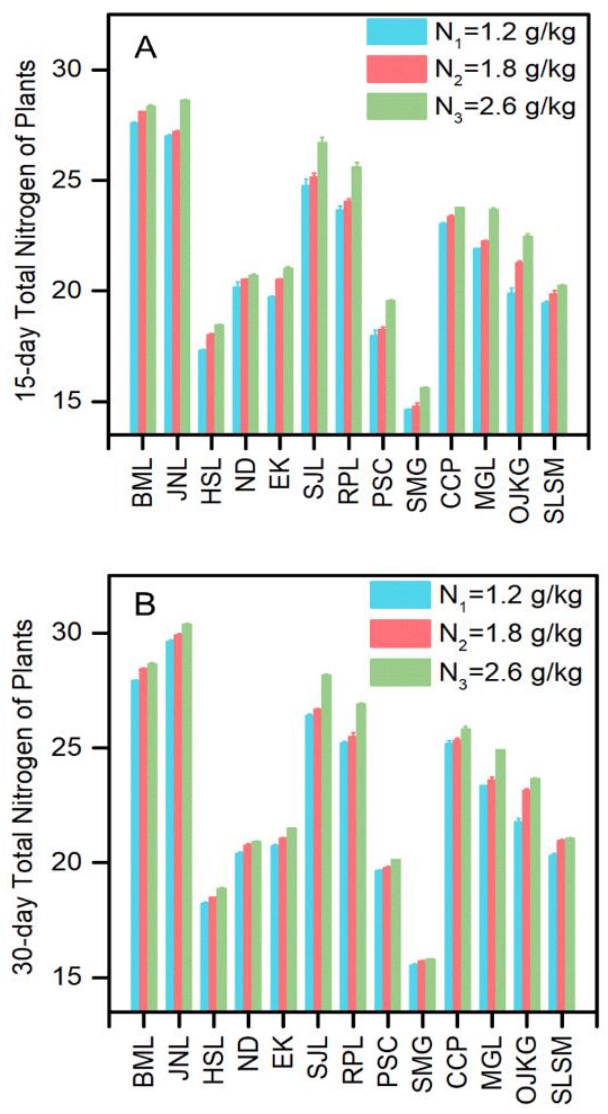

Figure 3. Plants total nitrogen concentration in different days under three nitrogen levels: (A) 15-day culturing time, (B) 30-day culturing time.

Measurement: On an ultraviolet spectrophotometer, ammonia-free water was used as a reference, and samples were tested at the wavelengths of $220 \mathrm{~nm}$ and $275 \mathrm{~nm}$, respectively. Check the corresponding total nitrogen concentration in the test solution on the calibration curve.

$A s=A s_{220}-2 A s_{275}$

$A b=A b_{220}-2 A b_{275}$

$A r=A s-A b$

where, $A s_{220}$ is absorbance of test solution at $220 \mathrm{~nm} ; A s_{275}$ is absorbance of test solution at $275 \mathrm{~nm} ; A b_{220}$ is absorbance of zero concentration blank test solution at $220 \mathrm{~nm} ; A b_{275}$ is absorbance of zero concentration blank test solution at $275 \mathrm{~nm}$.

The calculated total nitrogen content in soil is expressed in milligrams per kilogram (mg/kg):

$W=\frac{C \times V}{m \times(1-f)}$

where $C$ is the total nitrogen content can be found on the cali- 
bration curve, the unit is $\mathrm{mg} / \mathrm{L} ; V$ is constant volume of test solution, unit $\mathrm{mL} ; m$ is the weight of the sample, in $\mathrm{g} ; f$ is moisture content of the sample, expressed as a decimal.
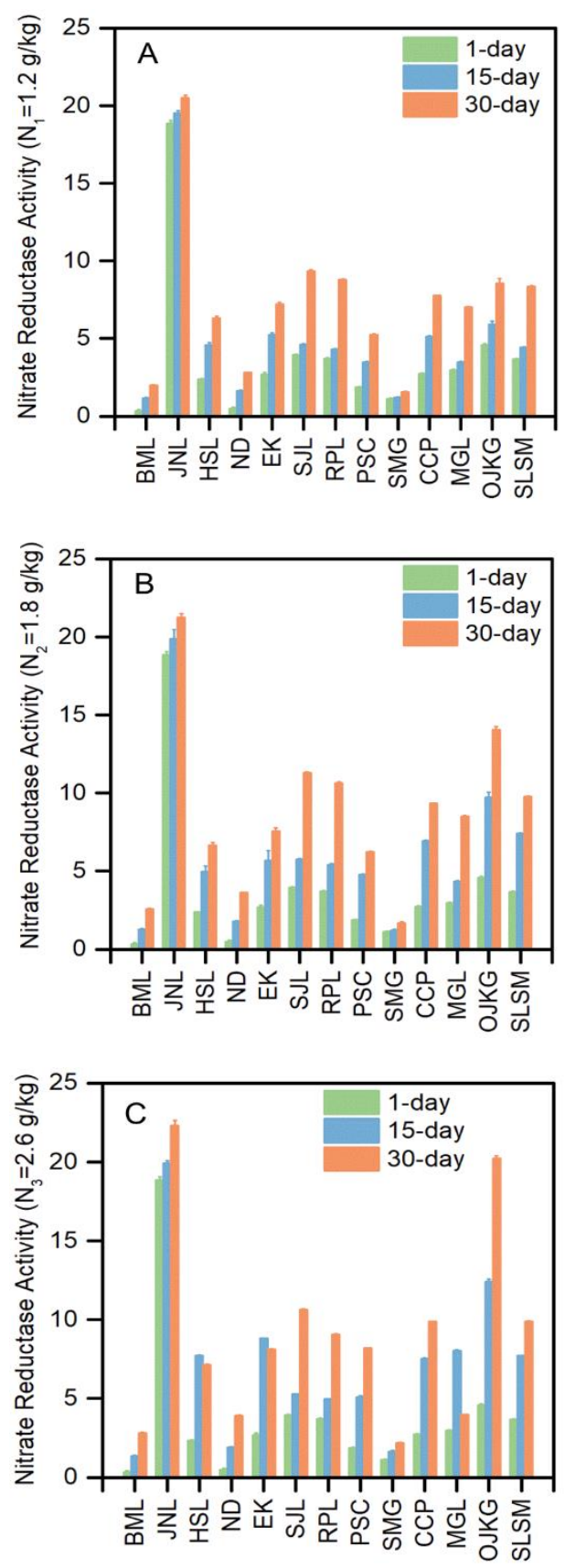

Figure 4. Nitrate reductase activity of plants for different days under three nitrogen concentrations (A) $\mathrm{N}_{1}=1.2 \mathrm{~g} / \mathrm{kg}$, (B) $\mathrm{N}_{2}=$ $1.8 \mathrm{~g} / \mathrm{kg}$, and $(\mathrm{C}) \mathrm{N}_{3}=2.6 \mathrm{~g} / \mathrm{kg}$.

\section{Results and Discussions}

\subsection{Variation of Nitrogen Concentration in Soil}

Figure 1 shows the total soil nitrogen concentration (TSN) changes and TSN remove ratio after each plant was cultivated for 30 days under different nitrogen levels. Compared with the blank control (CK), the TSN of all kinds of plants reduces for three nitrogen levels, which means that plants can effectively absorb nitrogen in the soil. Under the same nitrogen level, three types of plants (shrub, arbor, and herb) have similar average values of soil nitrogen absorption performance, indicating that there is no relationship between the soil nitrogen absorption ability and plant species. Specifically, SJL and RPL have the largest absorption ability in all levels. Almost all plants exhibit similar absorption trend under three nitrogen levels, however, it is worth mention that absorption ability of EK and MGL decrease as the set soil nitrogen concentration rises. Thus, these two plants are supposed not adapt to a high nitrogen environment and not suitable for the high nitrogen remove. On the other hand, OJKG displays increased nitrogen absorption property at high nitrogen concentration. Consequently, they are the first choice for sever nitrogen polluted soil treatment. As shown in Figure 1B, the regulation of plants remove ratio is as follows: remove ratio of $\mathrm{N}_{1}>\mathrm{N}_{2}>\mathrm{N}_{3}$. However, under the high nitrogen concentration, the nitrogen remove amount is the highest. Furthermore, CCP have lowest nitrogen removal rates under three nitrogen level; thus, they are not advisable for embankment plants. BML, EK, and SJL show relatively high removal rate and have high application prospect.
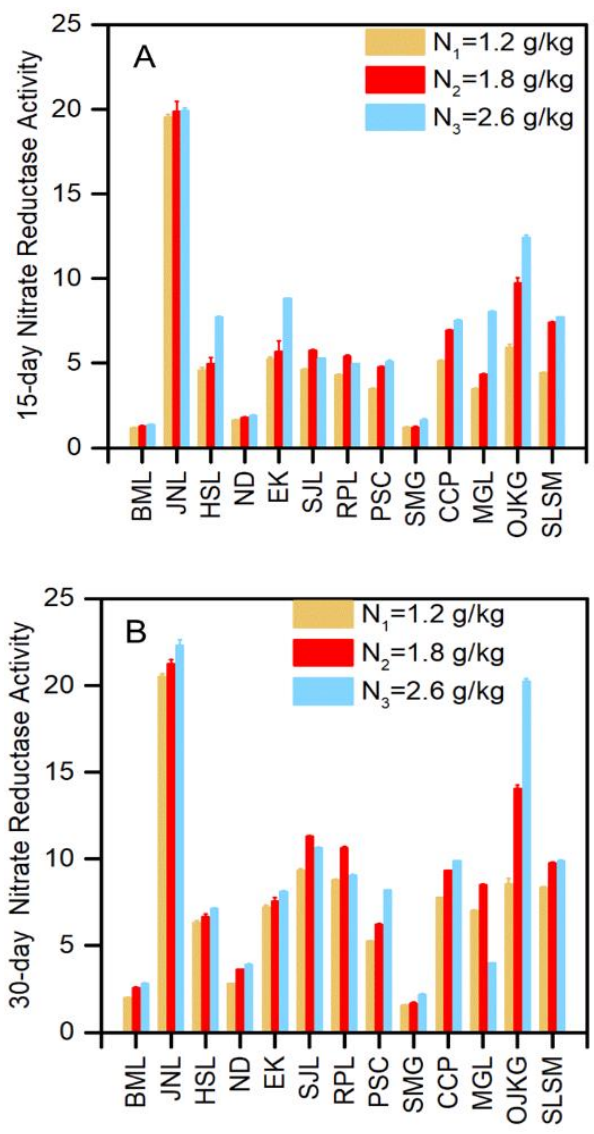

Figure 5. Nitrate reductase activity of plants for different days under three nitrogen concentrations. (A) 15-day culturing time, (B) 30-day culturing time. 

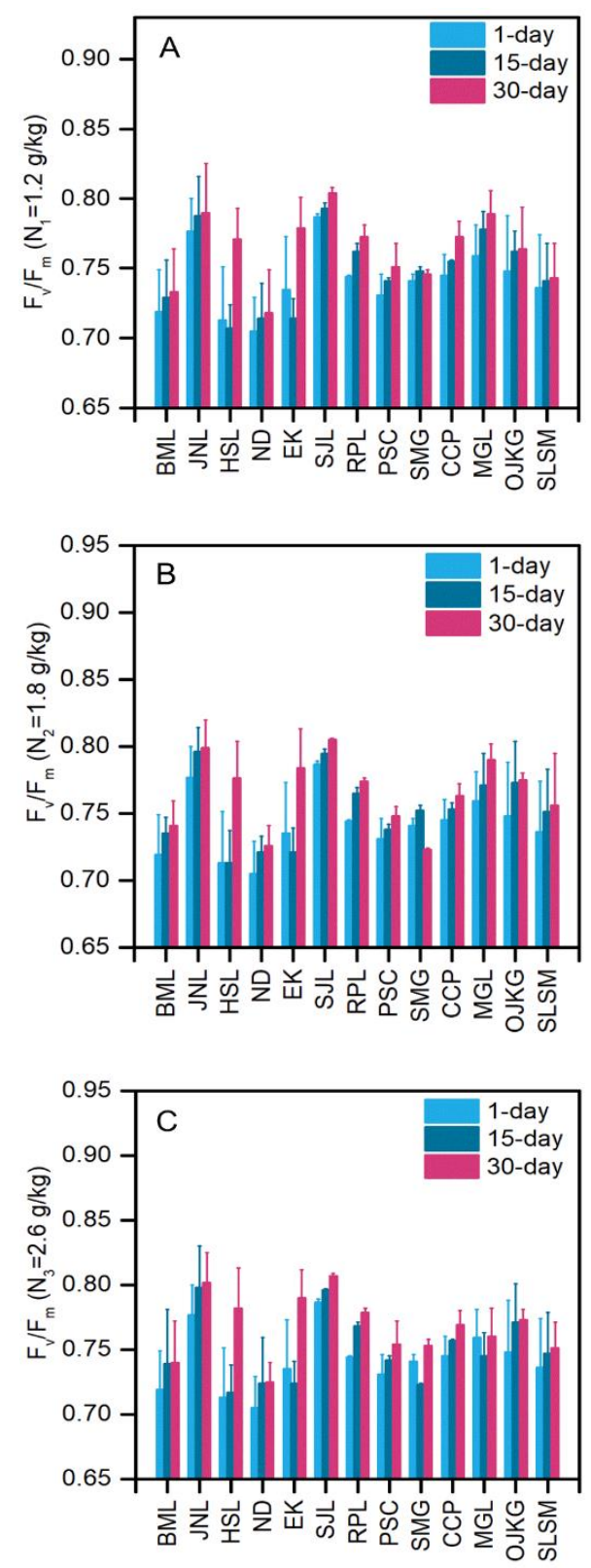

Figure 6. Optimal photochemical efficiency of PS II in the dark $\mathrm{F}_{\mathrm{v}} / \mathrm{F}_{\mathrm{m}}$ under three nitrogen concentrations (A) $\mathrm{N}_{1}=1.2 \mathrm{~g} / \mathrm{kg}$, (B) $\mathrm{N}_{2}=1.8 \mathrm{~g} / \mathrm{kg}$, and (C) $\mathrm{N}_{3}=2.6 \mathrm{~g} / \mathrm{kg}$.

\subsection{Total Nitrogen Content in Plant Leaves}

Results of plants total nitrogen concentration (PTN) are shown in Figure $2 \sim 3$. Apparently, at three nitrogen levels, leaves' PTN of all plants increase during the cultivation period. Under low nitrogen concentration, plants show high PTN increment at 30-day, while at middle and high nitrogen concentrations, high increment points occurred at 15-day. Although PTN still keep increasing from 15-day to 30-day under middle and high nitrogen levels, the growth ratios are low. In details, SMG, HSL, ND, EK, and PSC have relatively low PTN, even though HSL and EK show high PTN growth with increasing culture time. Therefore, these five plants are not suitable for planting in river areas with eutrophication problems. JNL maintains highest PTN and relatively high PTN increments at all three nitrogen levels. Other plants, such as BML, SJL, RPL, CCP, MGL, and OJKG possess high PTN; however, the PTN increments of CCP are relatively low. This result is almost consisted with the soil total nitrogen result, low STN removal ratio of CCP due to inherent qualities of high PTN and low PTN increments. The results of the same plant under different nitrogen levels in the same culture period show that PTN of JNL, SJL, RPL, and OJKG rise higher with the in-creasing of nitrogen level.
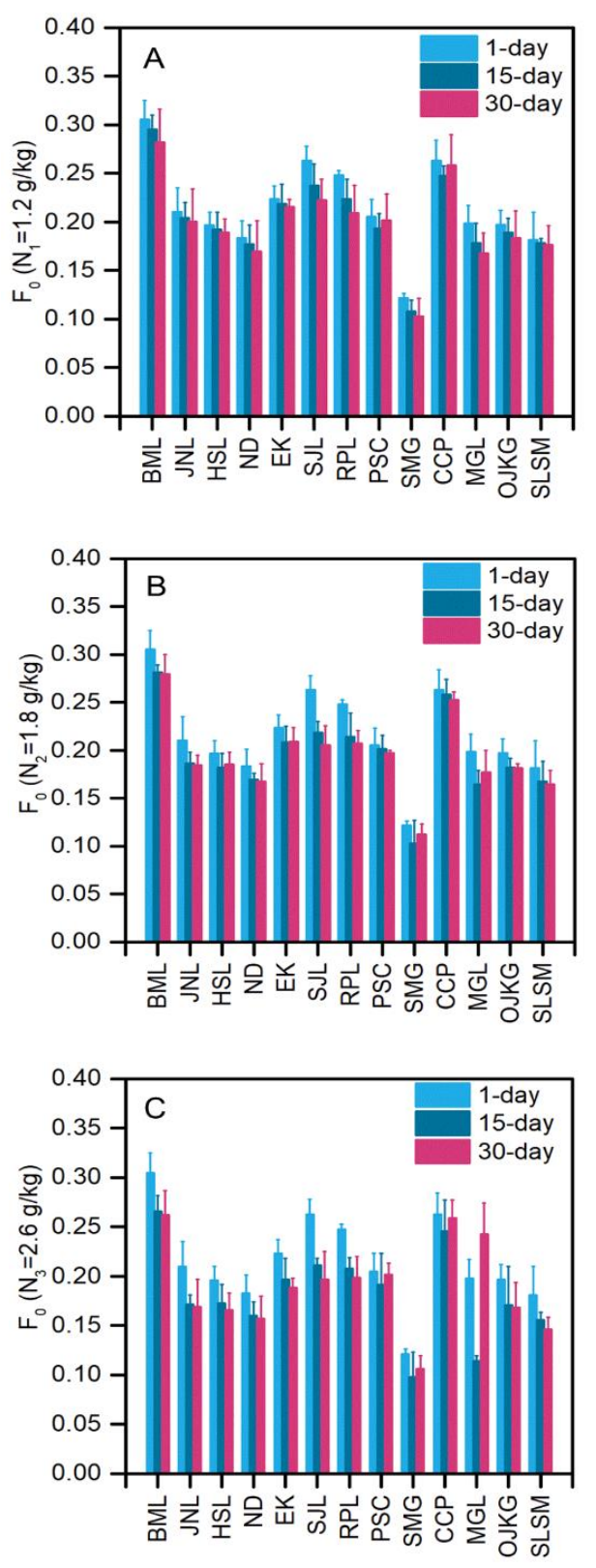

Figure 7. Minimal fluorescence $\mathrm{F}_{0}$ under under three nitrogen concentrations (A) $\mathrm{N}_{1}=1.2 \mathrm{~g} / \mathrm{kg}$, (B) $\mathrm{N}_{2}=1.8 \mathrm{~g} / \mathrm{kg}$, and (C) $\mathrm{N}_{3}$ $=2.6 \mathrm{~g} / \mathrm{kg}$. 

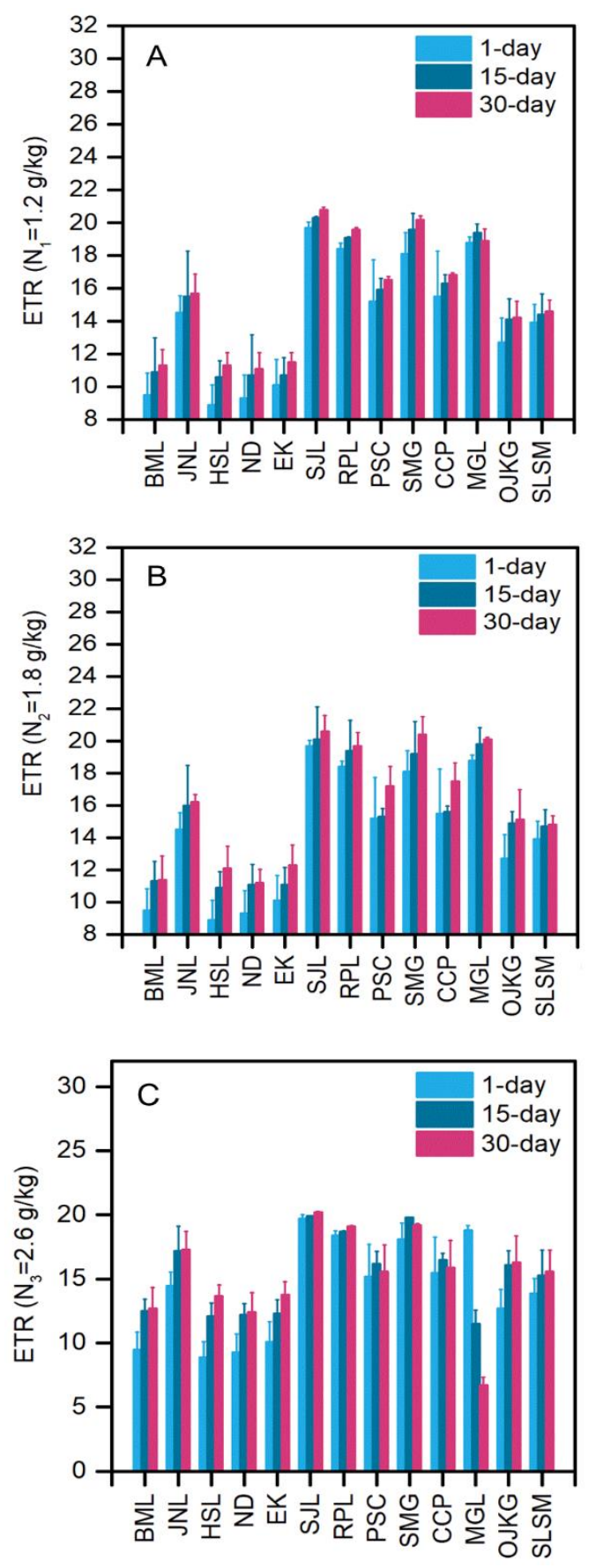

Figure 8. ETR parameter under three nitrogen concentrations (A) $\mathrm{N}_{1}=1.2 \mathrm{~g} / \mathrm{kg}$, (B) $\mathrm{N}_{2}=1.8 \mathrm{~g} / \mathrm{kg}$, and (C) $\mathrm{N}_{3}=2.6 \mathrm{~g} / \mathrm{kg}$.

\subsection{Chlorophyll Fluorescence Parameters}

Nitrogen utility of plant is closely related to photosynthesis. Plants absorb and use of nitrogen requires photosynthesis to provide a carbon scaffold to assimilate $\mathrm{NH}_{4}{ }^{+}$to $\mathrm{NO}_{3}{ }^{-}$(Pearson and Stewart, 1993). Chlorophyll fluorescence parameters are a set of variables or constant values used to describe the photosynthesis mechanism and physiological conditions of plants. They reflect the characteristics of plants "intrinsics" and are considered as an internal probe to study the relationship between plant photosynthesis and the environment (Li et al., 2006). Figure $6 \sim 8$ show parameters of $F_{v} / F_{m}, F_{0}$, and ETR, which are the main parameters used to characterize the chlorophyll fluorescence intensity. Optimal photochemical ef-ficiency of PSII in the dark $F_{v} / F_{m}$ reflects the efficiency of radon light energy conversion in PSII reaction center (Roháček, 2002). Under nonstress conditions, this parameter keep unchanged or only slightly change, which means that it is not affected by and growth conditions. On the other hand, $F_{v} / F_{m}$ decreases signifycantly under stress conditions (Roháček, 2002). Analyzed by SPSS software, there is no significant difference for all plants under $\alpha=0.05$ for three nitrogen levels. This result illustrates that all plants could adapt to the three living conditions. Minimal fluorescence $F_{0}$ is the fluorescence yield when the photosystem II (PSII) reaction center is fully open, and it is related to the leaf chlorophyll concentration (Roháček, 2002). Under low nitrogen level (shown in Figure 7A), only $\mathrm{F}_{0}$ of BML shows signifycant difference $(\alpha=0.05)$, it decreases gradually as the culture time extends. Under middle nitrogen level (shown in Figure $7 \mathrm{~B}), \mathrm{F}_{0}$ of BML and JNL are significant difference ( $\left.\alpha=0.05\right)$; they have similar decline trend, and the difference occur between the 1-day and the 15-day. Under high nitrogen level (shown in Figure 7C), there are significant difference $(\alpha=0.05)$ for JNL, SJL, RPL, and MGL. JNL, SJL, and RPL show identical reduction as the low and middle level, but they have higher reduction ratio, compared to high level. $\mathrm{F}_{0}$ of MGL decreases from 1-day to 15-day but increases from 15-day to 30-day, and $\mathrm{F}_{0}$ of 30day even higher than that of 1-day. The result is speculated to be caused by the adaptation of plants to the environ-ment. MGL could only alive in high nitrogen environment for a short period. ETR is the apparent electron transfer efficiency at the actual light intensity (Massacci et al., 2008). The ETR values of the trees and herbs does not reach significant differences $(\alpha$ $=0.05$ ) at the three nitrogen concentrations (except for the MGL at high concentrations). As for shrub, there are significant differences $(\alpha=0.05)$ in ETR values at three nitrogen concentrations for JNL and BML. They climb with increasing culture time.

\subsection{Chlorophyll Content}

As an important material for photosynthesis, chlorophyll can not only reflect the growth state of plant leaves, but also reflect the nutrient level of leaves to a certain extent ( $\mathrm{Su}$ et al., 2011). Figure 9 shows the chlorophyll content of plants under three nitrogen levels. Almost all plants have an increased chlorophyll content with the extension of culture time under three nitrogen levels (except MGL at high nitrogen level). Under low and middle concentration, JNL shows highest chlorophyll content at the first day, but it is exceeded slightly by SJL at the 30-day. This result illustrates that SJL adapts better to this nitrogen environment. Moreover, BML, RPL, and MGL also show relatively high chlorophyll content under low and middle nitrogen levels. There are different regulations under high nitrogen level. BML and JNL show approximately the same chlorophyll content at 15-day and 30-day. Chlorophyll content of MGL decreases with increasing culture time (Xin et al., 2018). 

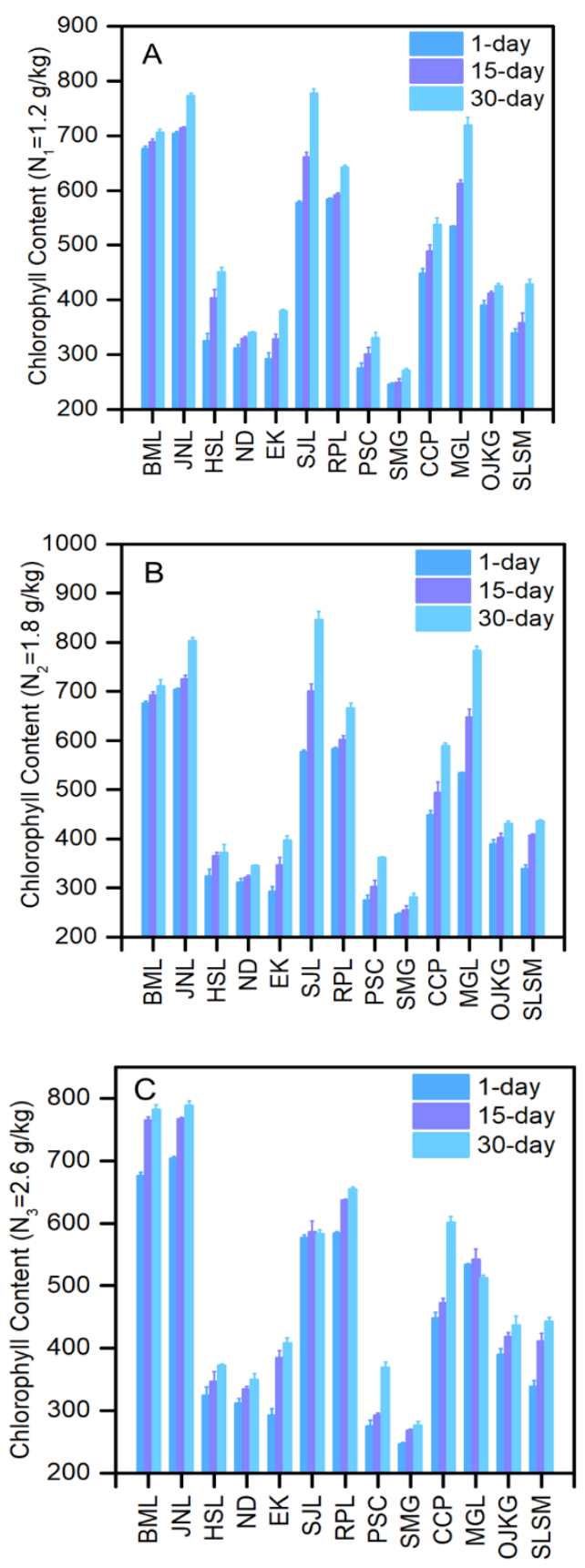

Figure 9. Chlorophyll content under three nitrogen concentrations (A) $\mathrm{N}_{1}=1.2 \mathrm{~g} / \mathrm{kg}$, (B) $\mathrm{N}_{2}=1.8 \mathrm{~g} / \mathrm{kg}$, (C) $\mathrm{N}_{3}=2.6 \mathrm{~g} / \mathrm{kg}$.

\section{Conclusions}

Through the measurement of soil total nitrogen (STN) concentration, plants total nitrogen (PTN) concentration, nitrate reductase activity (NRA), chlorophyll fluorescence parameters, and chlorophyll content, the adaptability of six kinds of arbor, five kinds of shrub, and two kinds of herb under different nitrogen concentrations were compared. Results show that there is no obvious relationship between the absorption and utilization of nitrogen and classifications of plants. In other words, the nitrogen utilization ability is determined by inherent properties of different plants, instead of arbor, shrub, or herb. STN result show that PEL and OJKG possess highest nitrogen remove ratio; BML and SJL have relatively high nitrogen utilization ability. PTN result demonstrate that JNL has the highest PTN value, besides, BML, SJL, RPL, MGL, and OJKG also have rarely high PTN value and PTN increase ratio. Furthermore, JNL, SJL, RPL, and OJKG show high NRA under three nitrogen levels. Fv/Fm value demonstrate that no plant lives under stress environment, which means that all plants can adapt to three nitrogen levels. JNL, SJL, and RPL show reduced F0 value, which means PSII reaction center has higher activity. JNL and BML have increased ETR. In addition, BML, JNL, SJL, and RPL own high chlorophyll content. Comprehensively, JNL is the best choice for establishing ecological embankment in Lihe area, and BML, SJL, OJKJ, and RPL are also promising candidate.

\section{References}

Aguiar, T.R., Rasera, K., Parron, L.M., Brito, A.G., and Ferreira, M.T. (2015). Nutrient removal effectiveness by riparian buffer zones in rural temperate watersheds: The impact of no-till crops practices. Agricultural Water Management, 149, 74-80. https://doi.org/10.10 16/j.agwat.2014.10.031

Campbell, W.H., (1999). Nitrate reductase structure, function and regulation: Bridging the gap between biochemistry and physiology. Annual Review of Plant Physiology and Plant Molecular Biology, 50(1), 277-303. https://doi.org/10.1146/annurev.arplant.50.1.277

Cao, X., Song, C., Xiao, J., and Zhou, Y. (2018). The Optimal width and mechanism of riparian buffers for storm water nutrient removal in the Chinese Eutrophic lake Chaohu Watershed. Water, 10(10), 1489. https://doi.org/10.3390/w10101489

Chen, X.J., Huang, G.H., Fu, H.Y., An, C.J., Yao, Y., Cheng, G.H., and Suo, M.Q. (2017). Allelopathy Inhibitory Effects of Hydrodictyon reticulatum on Chlorella pyrenoidosa under Co-Culture and LiquorCultured Conditions. Water, 9(6), 416. https://doi.org/10.3390/w9 060416

Chen, Z.J., Tian, Y.H., Zhang, Y., Song, B.R., Li, H.C., and Chen, Z.H. (2016). Effects of root organic exudates on rhizosphere microbes and nutrient removal in the constructed wetlands. Ecological Engineering, 92, 243-250. https://doi.org/10.1016/j.ecoleng.2016. 04.001

Ge, Y., Zhang, K., and Yang, X. (2018). Long-term succession of aquatic plants reconstructed from palynological records in a shallow freshwater lake. Science of the Total Environment, 643, 312-323. https://doi.org/10.1016/j.scitotenv.2018.06.203

Hille, S., Andersen, D.K., Kronvang, B., and Baattrup-Pedersen, A. (2018). Structural and functional characteristics of buffer strip vegetation in an agricultural landscape - high potential for nutrient removal but low potential for plant biodiversity. Science of the Total Environment, 628-629, 805-814. https://doi.org/10.1016/j.scitotenv. 2018.02.117

Jasrotia, S., Kansal, A., and Mehra, A. (2017). Performance of aquatic plant species for phytoremediation of arsenic-contaminated water. Applied Water Science, 7(2), 889-896. https://doi.org/10.1007/s132 01-015-0300-4

Jiang W.J. and Pan H. (2010). Analysis of loss in digesting loss in measuring total nitrogen and solution. Environmental Science and Management, 35, 143-4. (In Chinese)

Korol, A.R., Ahn, C., and Noe, G.B. (2016). Richness, biomass, and nutrient content of a wetland macrophyte community affect soil nitrogen cycling in a diversity-ecosystem functioning experiment. Ecological Engineering, 95, 252-265. https://doi.org/10.1016/j.eco 
leng.2016.06.057

Kuglerová, L., Ågren, A., Jansson, R., and Laudon, H. (2014). Towards optimizing riparian buffer zones: Ecological and biogeochemical implications for forest management. Forest Ecology and Management, 334, 74-84. https://doi.org/ 10.1016/j.foreco.2014.08. 033

Li, L., Li, N.H., and Jiang, S.M., (2009). Experimental guidance of plant physiology module. Beijing: Science Press. ISBN:978703 0230539

Li, R.H., Guo, P., Michael, B., Stefania, G., and Salvatore, C. (2006). Evaluation of chlorophyll content and fluorescence parameters as indicators of drought tolerance in Barley. Agricultural Sciences in China, 5(10), 751-757. https://doi.org/10.1016/S1671-2927(06)601 20-X

Liu, L.R., Huang, C.Z., Huang, G., Baetz, B.W., and Pittendrigh, S.M. (2018). How a carbon tax will affect an emission-intensive economy: A case study of the Province of Saskatchewan, Canada. Energy, 159, 817-826. https://doi.org/10.1016/j.energy.2018.06.163

Liu, P., and Li, M.J. (2007). Plant physiology experiment technique. Beijing: Science Press. ISBN:9787030202901

Massacci, A., Nabiev, S.M., Pietrosanti, L., Nematov, S.K., Chernikova, T.N., Thor, K., and Leipner, J. (2008). Response of the photosynthetic apparatus of cotton (Gossypium hirsutum) to the onset of drought stress under field conditions studied by gas-exchange analysis and chlorophyll fluorescence imaging. Plant Physiology and Biochemistry, 46(2), 189-195. https://doi.org/10.1016/j.plaphy. 2007.10.006

Mo, S., Zhang, X., Tang, Y., Liu, Z., and Kettridge, N. (2017). Effects of snails, submerged plants and their coexistence on eutrophication in aquatic ecosystems. Knowledge \& Management of Aquatic Ecosystems, (418), 44. https://doi.org/10.1051/kmae/2017034

Pearson, J., Stewart, and G.R. (1993). The deposition of atmospheric ammonia and its effects on plants. New Phytologist, 125(2), 283305. https://doi.org/10.1111/j.1469-8137.1993.tb03882.x

Rezania, S., Din, M. F.M., Taib, S.M., Dahalan, F.A., Songip, A.R., Singh, L., and Kamyab, H. (2016). The efficient role of aquatic plant (water hyacinth) in treating domestic wastewater in continuous system. International Journal of Phytoremediation, 18(7), 679-685. https://doi.org/10.1080/15226514.2015.1130018

Ma, M. (2018) Riparian Buffer Zone for Wetlands. In: Finlayson C. et al. (eds) The Wetland Book. Springer, Dordrecht. https://doi.org/10. 1007/978-90-481-9659-3 53

Roháček, K. (2002). Chlorophyll fluorescence parameters: The definetions, photosynthetic meaning, and mutual relationships. Photosynthetica, 40, 13-29. https://doi.org/10.1023/A:1020125719 386

Schilling, K.E., Jacobson, P.J., and Wolter, C.F. (2018). Using riparian Zone scaling to optimize buffer placement and effectiveness. Landscape Ecology, 33(1), 141-156. https://doi.org/10.1007/s10980-01 7-0589-5

Song, P., Huang, G.H., An, C.J., Shen, J., Zhang, P., Chen, X.J., Shen, J., Yao, Y., Zheng, R.B., and Sun, C.X., (2018). Treatment of rural domestic wastewater using multi-soil-layering systems: Performance evaluation, factorial analysis and numerical modeling. Science of the total environment, 644, 536-546. https://doi.org/10. 1016/j.scitotenv.2018. 06.331

Srivastava, J.K., Chandra, H., Kalra, S.J.S., Mishra, P., Khan, H., and Yadav, P. (2017). Plant-microbe interaction in aquatic system and their role in the management of water quality: a review. Applied Water Science, 7(3), 1079-1090. https://doi.org/10.1007/s13201016-0415-2

Stottmeister, U., Wießner, A., Kuschk, P., Kappelmeyer, U., Kästner, M., Bederski, O., Müller, R.A., and Moormann, H. (2003). Effects of plants and microorganisms in constructed wetlands for wastewater treatment. Biotech. Advances. 22. 93-117. https://doi.org/10. 1016/j.biotechadv.2003.08.010

Stutter, M.I., Chardon, W.J., and Kronvang, B. (2012). Riparian buffer strips as a multifunctional management tool in agricultural landscapes: Introduction. Journal of Environmental Quality, 41(2), $297-$ 303. https://doi.org/10.2134/jeq2011.0439

Su, Y.L., Sun, Q.Z., Zhang, L.J., and Wu, Y.H. (2011). Coupling effect of water and fertilizer on chlorophyll content and nitrate reductase activity in Alfalfa leaves. Chinese Jou Grassland, 3, 52-56. (In Chinese)

Sweeney, B.W., and Newbold, J.D. (2014). Streamside forest buffer width needed to protect stream water quality, habitat, and organisms: A literature review. Journal of the American Water Resources Association, 50(3), 560-584. https://doi.org/10.1111/jawr.12203

Truu, J., Truu, M., Espenberg, M., Nõlvak, H., and Juhanson, J. (2015). Phytoremediation and Plant-Assisted Bioremediation in Soil and Treatment Wetlands: A Review. The Open Biotechnology Journal, 9(1), 85-92. https://doi.org/10.2174/1874070701509010085

Uusi-Kämppä, J. and Jauhiainen, L. (2010). Long-term monitoring of buffer zone efficiency under different cultivation techniques in boreal conditions. Agriculture, Ecosystems and Environment, 137(12), 75-85. https://doi.org/10.1016/j.agee.2010.01.002

Weller, N.A., Childers, D.L., Turnbull, L., and Upham, R.F. (2016). Aridland constructed treatment wetlands I: Macrophyte productivity, community composition, and nitrogen uptake. Ecological Engineering, 97, 649-657. https://doi.org/10.1016/j.ecoleng.2015. 05.044

Xie, Y.L., Xia, D.X., Ji, L., and Huang, G.H. (2018). An inexact stochastic-fuzzy optimization model for agricultural water allocation and land resources utilization management under considering effective rainfall. Ecological indicators, 92, 301-311. https://doi.org/10. 1016/j.ecolind.2017.09.026

Xin, X.Y., Huang, G.H., An, C.J., Huang, C., Weger, H., Zhao, S., Zhou, Y., and Rosendahl, S. (2018). Insights into the toxicity of triclosan to green microalga Chlorococcum sp. using synchrotronbased fourier trans-form infrared spectromicroscopy: biophysiological analyses and roles of environmental factors. Environmental science \& technology, 52(4), 2295-2306. https://doi.org/10.1021 /acs.est.7b05 533

Xu, Q., Chen, Q.W., Zhao, S.P., Liu, K., and Ma, J.F. (2016). Saving water and associated energy from distribution networks by considering landscape factors in pressure management and use of sistrict metered Areas. Journal of Environmental Informatics, 31(1), 65-73. https://doi.org/10.3808/jei.201700361

Xue, J., Liu, W., Zhang, G.S., and Zhou, Q. (2006). Effect of $\mathrm{La}^{3+}$ on soybean seedling nitrate reductase activity and solube protein content under supplemental UV-B radiation. Chinese Journal of Oil Crop Sciences. 28, 298-301. (In Chinese)

Yu, L., Li, Y.P., and Huang, G.H. (2019). Planning municipal-scale mixed energy system for stimulating renewable energy under multiple uncertainties-The City of Qingdao in Shandong Province, China. Energy, 166, 1120-1133. https://doi.org/10.1016/j.energy.20 18.10.157

Zak, D., Kronvang, B., Carstensen, M.V., Hoffmann, C.C., Kjeldgaard, A., Larsen, S.E., Audet, J., Egemose, S., Jorgensen, C.A., Feuerbach, P., Gertz, F., and Jensen, H.S. (2018). Nitrogen and phosphorus removal from agricultural runoff in integrated buffer zones. Environmental Science \& Technology, 52(11), 6508-6517. https://doi.org/10. 1021/ acs.est.8b01036

Zhang, C., Li, S., Qi, J., Xing, Z., and Meng, F. (2017). Assessing impacts of riparian buffer zones on sediment and nutrient loadings into streams at watershed scale using an integrated REMM-SWAT model. Hydrological Processes, 31(4), 916-924. https://doi.org/10. 1002/hyp.11073

Zhang, X., Liu, X., Zhang, M., Dahlgren, R.A., and Eitzel, M. (2010). A review of vegetated buffers and a meta-analysis of their mitigation efficacy in reducing nonpoint source pollution. Journal of Environmental Quality, 39, 76-84. https://doi.org/10.2134/jeq20 08.0496

Zhang, Y., Liu, X., Qin, B., Shi, K., Deng, J., and Zhou, Y. (2016). Aquatic vegetation in response to increased eutrophication and 
degraded light climate in Eastern Lake Taihu: Implications for lake ecological restoration. Scientific Reports, 6, 23867. https://doi.org/ $10.1038 /$ srep23867

Zhou, T., Wu, J., and Peng, S. (2012). Assessing the effects of landscape pattern on river water quality at multiple scales: A case study of the Dongjiang River watershed, China. Ecological Indicators, 23, 166-175. https://doi.org/10.1016/j.ecolind.2012.03.013

Zhou, Y., Huang, G., Zhu, H., Li, Z., and Chen, J. (2016). A factorial dual-objective rural environmental management model. Journal of Cleaner Production, 124, 204-216. https://doi.org/10.1016/J.JCL EPRO.2016.02.081

Zhu, S., Huang, X., Ho, S. H., Wang, L., and Yang, J. (2017). Effect of plant species compositions on performance of lab-scale constructed wetland through investigating photosynthesis and microbial communities. Bioresource Technology, 229, 196-203. https://doi.org/ 10.1016/j.biortech.2017.01.023 